\title{
Psychological Distress and Coping Strategies among Parents with Deaf and Mute Children
}

\author{
Rasha Galal Abdelrahman ${ }^{1}$, Maaly Ibrahim El-Malky ${ }^{2}$ and Mona Mohamed Abdel-Aziz ${ }^{\mathbf{3}}$ \\ (1) Nursing educator at Technical School of Nursing at Shebin El-Kom -Elmenofiya Governorate, \\ Egypt. (2) Professor of Psychiatric and Mental Health Nursing-Faculty of Nursing-Menoufia \\ University, Egypt and (3) Assistant Professor of Psychiatric and Mental Health Nursing-Faculty of \\ Nursing- Benha University, Egypt.
}

\begin{abstract}
Background: Deafness is one of the disabilities seen in all age group. Deafness in younger age group is an emerging health problem in Egypt. Deaf and mute child can negatively affect the emotional, mental, and physical health of the parents. Aim of study: The study aimed to assess psychological distress and coping strategies among parents with deaf and mute children. Design: A descriptive correlational research design was used. Setting: The study sample was conducted at ElAmal School for the deaf and dumb, Benha district at Qalubia governorate. Study subject: A convenience sample composed of 100 parents with deaf and mute children. Tools of data collection: The main three tools were used, I: An interviewing question is related to parents with deaf and mute child and their child. II: Depression, Anxiety and Stress Scale (DASS) to assess psychological distress and III: Brief Cope inventory to assess level of coping. Results: More than half of the studied parents have moderate level of depression and anxiety. Also, nearer to half of the studied parents have moderate level of stress and more than half of the studied parents have moderate level of coping strategies. There was statistically significant negative correlation between total stress symptoms and total coping. While, there was a highly statistically negative correlation between total coping of the studied parents and their total anxiety symptoms and total depressive symptoms and total stress symptoms. Conclusion: Parents with deaf and mute children are more prone to have psychological distress such as depression, anxiety and stress and have moderate coping strategies. Recommendations: Psycho-educational program for all parents of deaf and mute children enrolled in school focused on reducing parent psychological distress. Further studies for larger sample size should be done to generalize the results.
\end{abstract}

Key words: Coping Strategies, Deaf and Mute Children, Psychological Distress.

Muteness is defined as an absence of

\section{Introduction}

A child with a disability can be an overwhelming and pose many difficulties for parents. The long-term care of a child with deaf and mute frequently affects various areas in a parent's life domains (e.g., marriage, career, relationships), which can lead to stress, and often affects the overall functioning of the family. In addition, parents work to balance their marriages with demands that accompany having a child with special health care needs (Weldon, 2018). speech while conserving or maintaining the ability to understand the speech of others. Mutism is typically understood as an inability to speak on the part of a child due to an observed lack of speech from the point of view of others who know them such as family members, caregivers, teachers, or health professionals including doctors and speech and language pathologists. Muteness may not be a permanent condition, depending upon etiology (Butler, 2019). 
Deafness is defined as a degree of loss such that a person is unable to understand speech, even in the presence of amplification. In profound deafness, even the highest intensity sounds produced by an audiometer (an instrument used to measure hearing by producing pure tone sounds through a range of frequencies) may not be detected. In total deafness, no sounds at all, regardless of amplification or method of production, can be heard (Alqahtani, 2015).

Parents of children with a disabling condition face various challenges that are often not addressed, as resources tend to be primarily child focused. The first challenge faced by parents of children with a disability is social isolation. Family members and friends do not always understand the needs of a deaf and mute child and may not be able to provide child care support. In addition, activities, such as community outings and recreational activities are frequently reduced because of caregiver demands. A second challenge reported in the literature is that raising a child with a disability causes significant financial stress (Parish \&Cloud, 2019).

Coping with psychological stress through appraisal; therefore, appraisal is always considered to be the mediator (Lazarus, 2019). Cognitive appraisal and coping are critical mediators of the stressful person-environment relationships for parents as they navigate the immediate and long-term outcomes. Overall, stress appraisals result from perceived situational demands in relation to perceived coping resources; thus, the ability to successfully navigate those stressors is dependent on the person's coping strategies. People alter their circumstances to make it appear more favorable in an effort to cope. Coping is an individual's continuous effort in thoughts and actions to manage specific external or internal demands appraised to be challenging and overwhelming to the individual. In addition, coping is considered highly effective its effectiveness is determined by the ability to change over time and across different conditions (Folkman \& Lazarus, 2019).

Previous research has shown that with the appropriate support and guidance, parents of deaf and mute child can cope effectively with the many challenges presented and, in turn, become advocates for the child (Shilling et al., 2015). Therefore, the major goal of this study was to achieve a more thorough understanding of these parents as a fundamental building block for future research and practice. Statement of the problem although limited research exists pertaining to the psychological stress, coping process of deaf and mute child so, this study aimed to assess psychological distress and coping strategies among parents with deaf and mute children (Bayat et al., 2019).

\section{Significance of the study}

Deafness is one of the disabilities seen in all age group. Deafness in younger age group is an emerging health problem in our country. Permanent childhood hearing impairment can have a devastating impact on communication skills, educational attainment, mental health and quality of life, with a high cost to society (Sayed et al., 2018). There is no database about the magnitude and distribution of the hearing impairment problem in Egypt. Across the world, 466 million people have disabling hearing loss (over $5 \%$ of the world's population), of whom 34 million are children. Statistics released by the United Nations also indicate that, in Egypt alone, 7.5 million people suffer from deafness or hearing impairment (Humes, 2019).

Raising a child with disabilities is a particular challenge for parents. Meaningful psychological, physical and social demands arising out of the particular life situations of 
families with mute and deaf children with unique characteristic may overstrain the families' capacities, coping and resource and result in increasing risk parents, psychological problems like depression, anxiety and somatization symptoms (Alexander \& Walendzik, 2016). Lower family wellbeing creates negative cycle that can exacerbate the child problem. Conversely, improved family functions can positively impact child outcomes (Nes et al., 2014). So, this study aims to assess psychological distress and coping strategies among parents with deaf and mute children.

\section{Aim of the study}

This study aimed to assess psychological distress and coping strategies among parents with deaf and mute children

\section{Research questions:}

1. What is the psychological distress among parents with deaf and mute children?

2. What are the levels of psychological distress \& coping strategies among parents with deaf and mute children?

3. What is the relation between psychological distress and coping strategies among parents with deaf and mute children?

\section{Subject and methods}

\section{Research design:-}

A descriptive correlational design was utilized to fulfill the aim of this study.

\section{Research setting:-}

The study was conducted at El-Amal school for the deaf and dumb in Benha City Qaliobia Governorate, which is affiliated to Ministry of Education. This school consisted of 3 buildings. The first building for primary students, it take students from 5 years up-to 12 years the second building for preparatory students it take students from 12 years, up-to 14 years. The third building for secondary students it takes students from 14 years up-to 16 years.

\section{Research sampling:- Sample size:}

Based on the outcome of the previous study and at confidence interval (CI) $95 \%$ and at power analysis $80 \%$, the sample size was ranged from $80-100$, so that sample size was 100 parents of deaf and dumb childrens, according to equation by Yamane, (1976).

$$
\mathrm{n}=\frac{\mathrm{N}}{1+\mathrm{N}(\mathrm{e})^{2}}
$$

Where $\mathrm{n}$ is sample size

$\mathrm{N}$ is the total number of student

$\mathrm{e}$ is coefficient factor $=0.05 \%$

The sample number $=100$

$\mathrm{e}$ is coefficient factor $=0.05 \%$

\section{Subjects:}

A convenience sample of 100 parents of deaf and dumb children enrolled at primary and secondary school for deaf and dumb at Benha City, Qalubia governorate.

\section{According to the following inclusion} criteria:

- Agree to participate in the study

- Able to communicate

- Free from any chronic physical illness

- Free from any history of psychiatric and neurological disorders

\section{Tools of data collection:}

Three tools utilized for collecting data.

\section{Tool I: Structure Interview Questionnaire.}

The researcher was design it after reviewing the related literature and guidance of supervisors. It was written in an Arabic language for gathering data in relation to the following parts:

Part I: Socio-demographic data of parents such as age, sex, level of education, job, marital statuts, résidence, income and family stabilty.

Part II: Socio-demographic data of child, such as age, sex, number of siblings, the study stage and child ranking. 
Tool II: Depression, Anxiety and Stress Scale (DASS)

Depression, Anxiety, and Stress Scale developed by Lovibond Lovibond, (1995). The DASS consists of 21 items, is a selfreport screening tool which measures the frequency of behaviors or intensity of feelings based on three subscales of anxiety (DASSA) 7 items, depression (DASSD) 7 items and stress (DASS-S) 7 items. A DASS total score computed from the three subscale. Scores of items rated on a three point scale (i.e., from 0 $=$ "never" to 2 = always"'). The higher the score the worst the DASS.

\section{Scoring system for DASS:-}

This scores were converted to percent score. Scoring system was different as follow:

1. Depression: normal 0-9, mild 10-13, moderate 14-20, sever 21-27, extremely sever 28 and more.

2. Anxiety: normal $0-7$, mild $8-9$, moderate 10-14, sever 15-19, extremely sever 20 and more.

3. Stress: normal 0-14, mild 15-18, moderate 19-25, sever 26-33, extremely sever 34 and more.

\section{Tool III: Brief Cope Inventory.}

This inventory developed by Carver \& scheier, (1989), used to categorize the coping strategies used by parents. This scale consisted of 28 items categorized into Active avoidance coping included all of the items from the original Brief COPE subscales for the substance use, behavioral disengagement, self-blame, venting of emotions, and one item from the distraction scale (item no. 1, 4,6, 9, 11, 13, 16, 19, 21, 26). Problem-focused coping included all the items from the original Brief COPE, subscales for planning, active coping, seeking instrumental social support, and one item each from the acceptance and emotional social support scales $(12,15,17$,
18, 20, 24, and 28). Religious/Denial coping is a varied factor that included all the Brief COPE items for religious coping and denial (3, 8, 22, 27). Positive coping includes all items of Brief COPE of active coping, use of emotional support, planning, and use of instrumental support $(2,7,5,10,15,14$, and 25). Items are arranged in a 3-point Likert format (1=Never, $2=$ Sometimes, and $3=$ always).

\section{Scoring system for coping:}

This scores were converted to percent score. Scoring system was different as follow:

1. Active avoidance coping: Low $>15$, moderate 15-22, high < 22.

2. Problem focused coping: Low $>10$, moderate 10-15, high < 15 .

3. Religious \& denial coping: Low $>6$, moderate 6-9, high $<9$.

4. Positive support: Low $>10$, moderate 10-15, high $<15$.

\section{Scoring system for total coping:}

level of total coping : Low $>42$, moderate 42-63, high $<63$ score.

\section{Validity and reliability:-}

Arabic translation was done by the researcher for tools of the study and tested for their translation. Five experts from faculty of nursing, Menofia University and Faculty of Nursing, Benha University who checked the relevaney, comprehensiveness, clarity and applicability of the questions. According to their opinions modification were done and the final form was developed. The modification were (modify some words to give the right meaning of the phrase). Test retest reliability was done $r=0.95$ for DAS scale, while, $r=$ 0.91 for Brief coping scale.

\section{Pilot study:-}

After the tools have been designed, a pilot study was done before embrarking on the field work to check the clarity and feasibility of a designed tools to be sure that it was 
understood and to estimate the time needed to complete its items. It was carried out on a sample of (10 parents) who have deaf and mute child and who were excluded later from the main study sample. After its implementation and according to its result, the necessary modification were done.

\section{Ethical considerations:-}

All ethical issues were assured written consent has been obtained from each parents before conducting the interview and given them a brief orientation to the purpose of the study, they were also reassured that all information gathered would be kept confidentially and used only for the purpose of the study. Parents had right to withdrwal from the study at any time without giving any reasons.

\section{Field work:}

The process of data collection took a period three months from October 2020 to December 2020, 3 days/week, 1h/days/ every 3 days. The researcher started data collection by introducing herself to the participants. Then brief description of the purpose of the study and the type of questionnaire required to fill was given to each participant. Data collected were done through interviewing with parents during their waiting to receive their child after the end of school day on the individual basis. The researcher started to collect the data from parents; each interview lasted for 20-30 minutes.

\section{Statistical analysis:}

All data collected were organized, coded, computerized, tabulated and analyzed by using Statistical Pachage for Social Science (SPSS) programs version 20, which was used frequencies and percentages for qualitative describtive data and chi-square was used for relation tests, mean and standard deviation was used for quantitative data, person correlation ( $r$ ) was used for correlation analysis and degree of significance was identified.

\section{Results}

Table (1): Shows that less than two-thirds $(62 \%)$ of the studied parents their age ranged from 25 -30 years with mean age 31.54 \pm 2.14 . Majority of studied parents (90\%) and (93\%) respectively are female and are married, less than two-thirds $(60 \%)$ of them have primary learning; the majority (92\%) not work, about two thirds (64\%) their income not enough, and the majority $(84 \%)$ of them from rural area. It is observed that the majority (92\%) their family was stable.

Table (2): Shows that more than half $(52 \%)$ of studied children are less than 5 years and more than two thirds (69\%) of them are male. More than one third (36\%) of them have two siblings. More than half $(58 \%)$ of them at preschool age and more than half $(57 \%)$ of the studied child are the first.

Table (3): Illustrates that the highest total mean score and standard deviation among the studied parents for stress is $7.38 \pm 2.53$, while the lowest mean score for anxiety is $7.07 \pm$ 1.47 .

Figure (1): Shows that more than half of the studied parents $(56 \%, 57 \%)$ have moderate depression \& anxiety respectively. Also, nearer to half $(46 \%)$ of the studied parents have moderate level of stress.

Figure (2): Reveals that, more than two thirds of the studied parents $(70 \%)$ have moderate level of positive coping. More than half $(60 \%)$ have moderate level of religions \& denial coping, half of them (50\%) have moderate level of problem focused coping, \& less than half $(40 \%)$ have moderate level of active avoidance coping,

Figure (3): Illustrates that more than half $(51 \%)$ of the studied parents have moderate levels of coping strategies, about one fifth $(23 \%)$ had low level of coping strategies. 
Table (4): Shows that there was statistically significant negative correlation between total stress symptoms and total coping at $\mathrm{P}$ - value $=<05$, while, there was a highly statistically significant negative correlation between total coping of the studied parents and their total anxiety symptoms and total depressive symptoms at $\mathrm{P}$-value $=<000$.

Table (5): Reveals that there was a highly statistically significant negative correlation between total depressive symptoms and problem focused coping. There was a highly statistically significant positive correlation between total anxiety symptoms \& both of active avoidance coping, religious / denial coping and positive coping. There was a highly statistically significant positive correlation between total stress symptoms and active avoidance coping, while, there was statistically significant negative correlation between total stress symptoms and problem focused coping.

Table (1): Socio-demographic characteristics among the studied parents $(n=100)$.

\begin{tabular}{|c|c|c|}
\hline \begin{tabular}{|l|l|} 
Socio-demographic characteristics of parents $(n=100)$ \\
\end{tabular} & $\overline{\text { No }}$ & $\%$ \\
\hline \multicolumn{3}{|l|}{ Age ( years) } \\
\hline $25<30 y r s$ & 62 & 62.0 \\
\hline $30<45 \mathrm{yrs}$ & 15 & 15.0 \\
\hline $45<60 \mathrm{yrs}$ & 12 & 12.0 \\
\hline$\geq 50 \mathrm{yrs}$ & 11 & 11.0 \\
\hline Mean \pm SD & \multicolumn{2}{|c|}{ 31.54 \pm 2.14} \\
\hline \multicolumn{3}{|l|}{ Sex } \\
\hline Male & 10 & 10.0 \\
\hline Female & 90 & 90.0 \\
\hline \multicolumn{3}{|l|}{ Marital status } \\
\hline Married & 93 & 93.0 \\
\hline Divorced & 2 & 2.0 \\
\hline Widow & 5 & 5.0 \\
\hline \multicolumn{3}{|l|}{ Educational level } \\
\hline Not read or write & 20 & 20.0 \\
\hline Primary learning & 60 & 60.0 \\
\hline Secondary learning & 11 & 11.0 \\
\hline Universal learning & 9 & 9.0 \\
\hline \multicolumn{3}{|l|}{ Job } \\
\hline Work & 8 & 8.0 \\
\hline Not Work & 92 & 92.0 \\
\hline \multicolumn{3}{|l|}{ Income } \\
\hline Not enough & 64 & 64.0 \\
\hline Enough and save with it & 36 & 36.0 \\
\hline \multicolumn{3}{|l|}{ Residence } \\
\hline Rural & 84 & 84.0 \\
\hline Urban & 16 & 16.0 \\
\hline \multicolumn{3}{|l|}{ Family stability } \\
\hline Stable & 92 & 92.0 \\
\hline Not stable & 8 & 8.0 \\
\hline
\end{tabular}


Table (2): Socio-demographic characteristics of the deaf \&mute children for the studied parents $(\mathbf{n}=\mathbf{1 0 0})$.

\begin{tabular}{|c|c|c|}
\hline Socio-demographic characteristics of child & No & $\%$ \\
\hline \multicolumn{3}{|l|}{ Age(years) } \\
\hline less than 5 yrs & 52 & 52.0 \\
\hline $5<10 \mathrm{yrs}$ & 27 & 27.0 \\
\hline $10-<15$ & 13 & 13.0 \\
\hline$\geq 15 \mathrm{yrs}$ & 8 & 8.0 \\
\hline Mean \pm SD & \multicolumn{2}{|c|}{$6.48 \pm 1.99$} \\
\hline \multicolumn{3}{|l|}{ Sex } \\
\hline Male & 69 & 69.0 \\
\hline Female & 31 & 31.0 \\
\hline \multicolumn{3}{|l|}{ The number of siblings $(n=92)$} \\
\hline One & 16 & 16.0 \\
\hline Two & 36 & 36.0 \\
\hline Three & 20 & 20.0 \\
\hline Four and more & 20 & 20.0 \\
\hline \multicolumn{3}{|l|}{ The study stage } \\
\hline Preschool age & 58 & 58.0 \\
\hline Primary & 25 & 25.0 \\
\hline Preparatory & 10 & 10.0 \\
\hline Secondary & 7 & 7.0 \\
\hline \multicolumn{3}{|l|}{ Child ranking } \\
\hline The first & 57 & 57 \\
\hline The second & 26 & 26 \\
\hline The third & 10 & 10 \\
\hline The last & 7 & 7 \\
\hline
\end{tabular}

Table (3): Total mean scores \& standard deviation of depressive symptoms, anxiety symptoms $\&$ stress symptoms among the parents subject $(n=100)$.

\begin{tabular}{|l|c|c|c|c|}
\hline \multicolumn{1}{|c|}{ Scale } & Min & Max & Mean \pm SD & \% score \\
\hline \hline Total depression & .00 & 9.00 & $6.19 \pm 2.15$ & 68.8 \\
\hline Total anxiety & 4.00 & 11.00 & $7.07 \pm 1.47$ & 64.3 \\
\hline Total stress & 1.00 & 13.00 & $7.38 \pm 2.53$ & 56.8 \\
\hline $\begin{array}{l}\text { Total depression, } \\
\text { anxiety \& stress } \\
\text { symptoms }\end{array}$ & 7.00 & 33.00 & $20.64 \pm 5.10$ & 62.5 \\
\hline
\end{tabular}




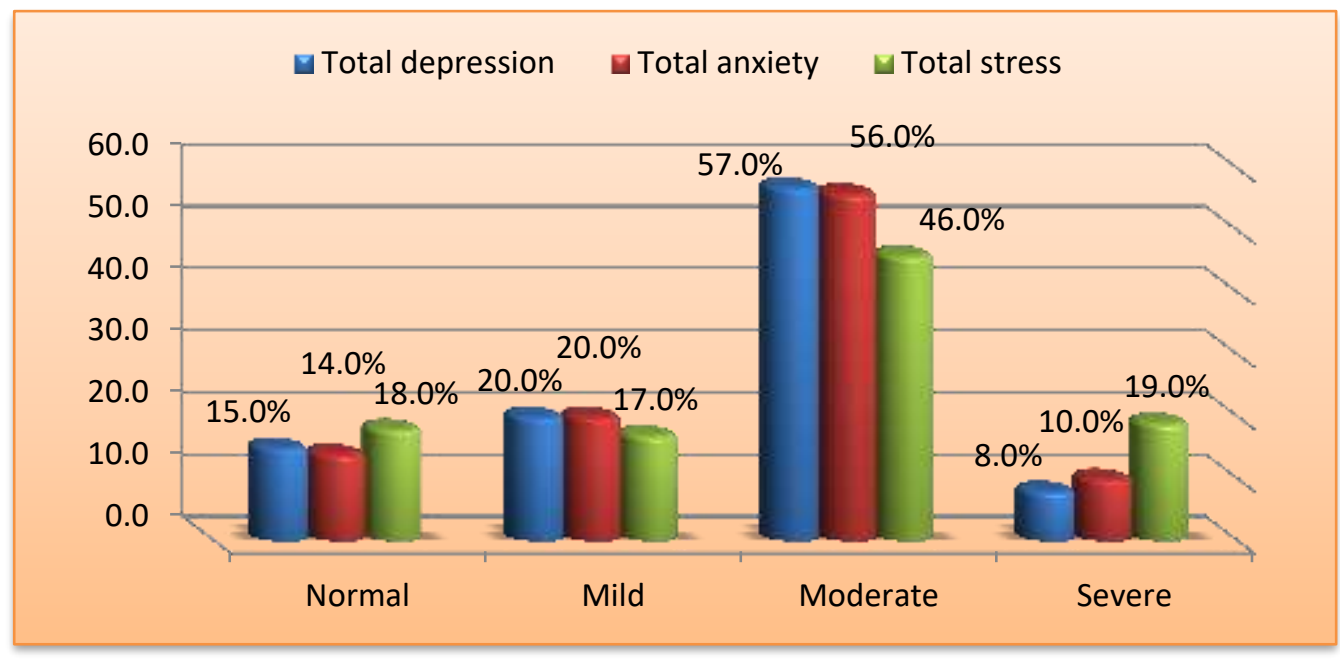

Figure (1): Percentage distribution of the level of DASS among studied parent $(n=100)$.

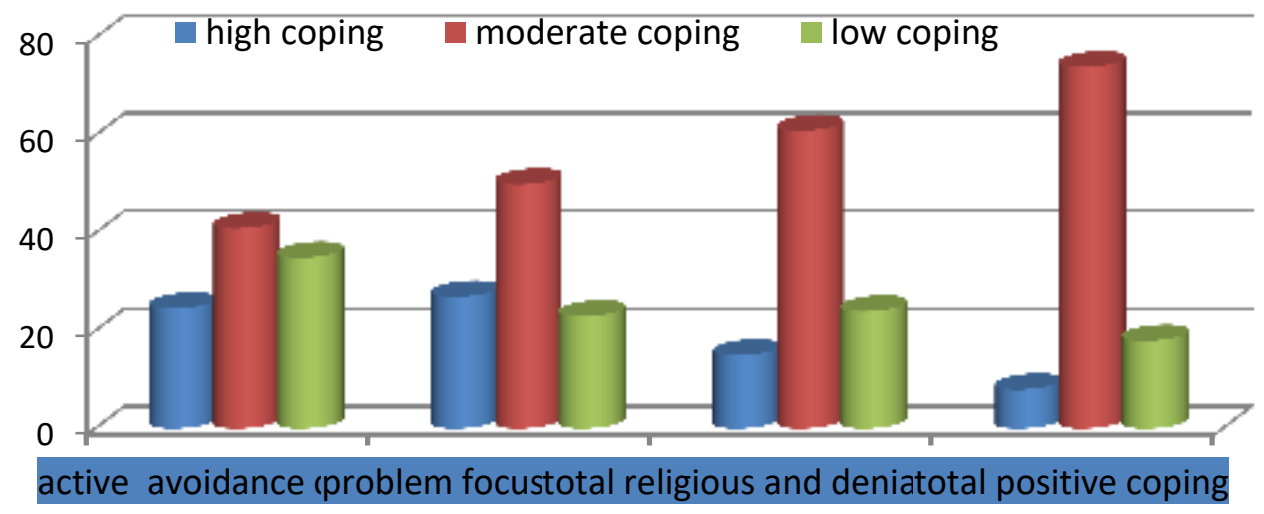

Figure (2): Percentage distribution of the total coping subscales among the studied parents $(\mathbf{n}=100)$.

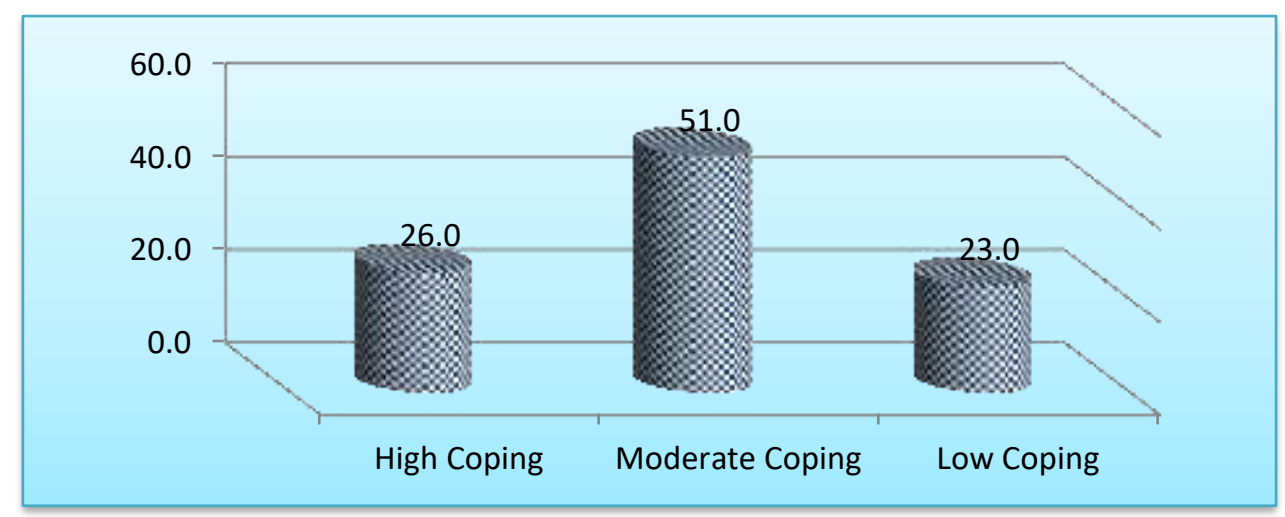

Figure (3): Level of total coping strategies among the studied parents $(n=100)$

Table (4): Correlation matrix between total coping and both of total depressive symptoms, total anxiety symptoms and stress symptoms (total DASS) among the studied parents $(n=100)$

\begin{tabular}{|c|c|c|c|c||}
\hline \multirow{2}{*}{ Scale } & & $\begin{array}{c}\text { Total } \\
\text { depression }\end{array}$ & $\begin{array}{c}\text { Total } \\
\text { anxiety }\end{array}$ & $\begin{array}{c}\text { Total } \\
\text { stress }\end{array}$ \\
\hline \multirow{2}{*}{ Total coping } & $\mathrm{r}$ & -.457 & -.383 & -.223 \\
\cline { 2 - 5 } & $\mathrm{p}$-value & $.000 * *$ & $.000 * *$ & $.026 *$ \\
\hline
\end{tabular}


Table (5): Correlation between total subscale of coping and total subscale of DASS among the studied parents $(\mathrm{n}=\mathbf{1 0 0})$

\begin{tabular}{|c|c|c|c|c|}
\hline \multicolumn{2}{|c|}{ Scale } & $\begin{array}{c}\text { Total } \\
\text { depression }\end{array}$ & $\begin{array}{c}\text { Total } \\
\text { anxiety }\end{array}$ & $\begin{array}{c}\text { Total } \\
\text { stress }\end{array}$ \\
\hline \multirow{2}{*}{ Active avoidance coping } & $\mathrm{r}$ & .074 & .553 & $.322^{* *}$ \\
\cline { 2 - 5 } & $\mathrm{p}$-value & .464 & $.000^{* *}$ & $.001^{* *}$ \\
\hline \multirow{2}{*}{ Problem - focused coping } & $\mathrm{r}$ & -.499 & $-.029-$ & -.463 \\
\cline { 2 - 5 } & $\mathrm{p}$-value & $.000^{* *}$ & .776 & $.000^{* *}$ \\
\hline \multirow{2}{*}{ Religious/ denial coping } & $\mathrm{r}$ & -.145 & -.599 & -.179 \\
\cline { 2 - 5 } & $\mathrm{p}$-value & .150 & $.000^{* *}$ & .075 \\
\hline \multirow{2}{*}{ Positive coping } & $\mathrm{r}$ & -.186 & .365 & -.149 \\
\cline { 2 - 5 } & $\mathrm{p}$-value & .064 & $.000^{* *}$ & .139 \\
\hline
\end{tabular}

\section{Discussion}

Having a child with developmental or psychological problems is always stressful for their parents who are taking care of them, even when the child is a grown up person, which would cause a constant incompatibility of parents with their child's disability. Several researchers have found that the 'psychological health' of the parents influences the quality of care children. Preoccupation with guilt, blame, or reduced self-esteem may divert parental attention from salient aspects of child rearing such as nutrition, recreation, education and household organization. Financial strain of providing medical and quality care to these children may add to parental stress (Mahoney, 2020). Therefore, the study aimed to assess psychological distress and coping strategies among parents with deaf and mute children.

According to the socio-demographic characteristics, the results of the present study revealed that less than two-thirds of the studied parents their age ranged from $25-30$ years. This finding was similar to the study done by Katz, (2019) found that, most of parents of his sample was in the age group (25 -30) years old. In addition Druss, (2019) showed that, the age group of the studied parents were between 25 to 30 years old.

As regard to sex, the results of the present study revealed that majority of studied parents are female. This may be due to the mothers are the first support of their children and accompanied them to school. Where most of males are at their work this finding was similar to the study done by Barnard, (2018) his results reflected that the majority of his sample were females and married. This finding also similar to the study done by Trute et al, (2020) studied the psychological distress and coping strategies to parents with deaf and mute child and his results reflected that the majority of his sample was females.

Also the result of this study showed that, more than half of the child for the studied parents at preschool age. This result may be due to the fact of majority of the mute child for the studied parents less than 5 years old which mean that they are at preschool age. This result were similar to Christiaan, (2019) found that more than half of his studied sample were less than 5 years old and they are at preschool age. On the other hand, Beitmans (2018) showed that the majority of the child of studied parents was primary and preparatory stage. 
Concerning educational level of the studied parents, this study results showed that less than two-thirds of them have primary learning. On Contrast, in a study done by Parish \& Cloud, (2019) revealed that, the percentage was higher in parents with a college degree. This could be due to cultural deference in the study sample

According to parent's job, the majority of the studied parents not work. This result may be due to lack of the opportunity of work or being responsible for caring of their deaf and mute children. This results were on the same line with the study done by Christiaan, (2019) that studied the coping strategies of parents with deaf or mute children and found that majority of his sample were females and not work. While this study disagreement with Parish \& Clouds (2019), revealed that, the Percentage was higher among parents who were working and economically stable.

According to socio-demographic characteristics of the child for the studied parents, the result of this study showed that more than half of studied child are less than 5 years. This result on the same line with Christiaan, (2019) and found that more than half of his studied sample was less than 5 years old. On the other hand, these results were contradicted with the study done by Beitman, (2018) showed that the majority of studied parents their child age more than 5 years old.

Regarding to sex, the present study showed that, more than two thirds of them are male. Because most male has fragile ear drum. These results on the same line with Benjamin, (2019) found that majority of his samples were male. On the other hand Andrew, (2018) studied psychological wellbeing of parents with deaf and mute child and reflected that more than two thirds of his studied samples was females.

Also the result of this study showed that, more than half of the child for the studied parents at preschool age. This result may be due to the fact of majority of the mute child for the studied parents less than 5 years old which mean that they are at preschool age. This result were similar to Christiaan, (2019) found that more than half of his studied sample were less than 5 years old and they are at preschool age. On the other hand, Beitmans (2018) showed that the majority of the child of studied parents was primary and preparatory stage.

Regarding to total level of depression, anxiety and stress among studied parent. This study showed that more than half of the studied parents have moderate depression and anxiety. Also, nearer to half have moderate level of stress. These findings may be related to the fact that having a child with developmental or psychological problems is always stressful for their parents who are taking care of them, even when the child is a grown up person, which would cause a constant incompatibility of parents with their child's disability. These parents, other than bearing financial pressures, are always facing emotional pressures such as feeling ashamed or feeling guilty, anxiety and stress.

Concerning to stress level, These result similar with Carney, (2020) showed that the parents with deaf and mute child have stress because they face greater challenges that make it necessary for them to be involved in extraordinary care, giving routines and specialized help and services. These problems increase parenting stress. These results also similar to Dyson, (2020) showed that higher demands are placed on parents with deaf and mute children particularly on their time and resources. Also Forgays et al., (2020) on the same line of the finding, who also stated that higher demands placed on the parents which increase stress level on the parents.

Regarding to anxiety level, the result similar with Martin, (2020) showed that parents with deaf and mute child have 
abnormal level of anxiety because they investing a lot of time with their child to meet their needs, he also said that the more time spend with the child, the more anxiety a parent feels. Quitter et al., (2020) also in the same line with these findings, who showed that the deaf and mute child has abnormal level of anxiety and have a harder time adjusting emotionally.

Concerning to depression level, these result similar with result of Price-Bonham \& Addison, (2020) showed that parents with deaf and mute child have feeling of depression, social isolation, and embarrassment. In the same line an exploratory study conducted by Asberg et al., (2019) showed that communication barrier between parents and the child may be predictor of depression, anxiety and stress.

According to the correlation between total coping and both total depressive symptoms, total anxiety symptoms and stress symptoms (total DASS) among the studied parents this study showed that there was statistically significant negative correlation between total stress symptoms and total coping this may be due to parent with psychological distress such as depression, anxiety and stress are prone to have impaired of their coping strategies due to burden from their children. This result on the same line with Shin, (2019) reflected that statistically significant negative correlation between total stress symptoms and total coping.

The study result showed that there was a highly statistically significant negative correlation between coping of the studied parents and their total anxiety symptoms \& total depressive symptoms because the more parents anxiety have when less coping mechanism used. This result agreement with Shin, (2019) revealed that a highly statistically significant negative correlation between total coping of the studied parents and their total anxiety symptoms and depressive symptoms.

Furthermore, the correlation between total subscale of coping and total DASS among the studied parents, this study showed that a highly statistically significant negative correlation between total depressive symptoms \& problem focused coping. Because problem focused coping is ineffective when depressive symptoms increase. This result on the same line with Mahoney, (2020) represented that, a highly statistically significant negative correlation between total depressive symptoms and problem focused coping. The parents of deaf and mute children must face the situation; focus on the problem and active management to all the condition to avoid any stress.

Also, this result agreement with Armstrong, (2020) showed that a highly statistically significant negative correlation between total depressive symptoms and problem focused coping among parent. Furthermore there are also a highly statistically significant positive correlation between total anxiety symptoms and both of active avoidance coping, religious / denial coping and positive support which on the same line with the findings of the current study.

Moreover, the current study showed that there was a highly statistically significant positive correlation between total stress symptoms and active avoidance coping, while, there with a statistically significant negative correlation between total stress symptoms and problem focused coping because Active avoidance coping is effective in reducing stress symptoms. This results agreement with Montes, (2018) showed that there was a highly statistically significant positive correlation between total stress symptoms and active avoidance coping and there was statistically significant negative 
correlation between total stress symptoms and problem focused.

\section{Conclusion}

More than half of the studied parents have moderate level of depression and anxiety. Also, nearer to half of the studied parents have moderate level of stress and more than half of the studied parents have moderate level of coping strategies. There was a statistically significant negative correlation between total stress symptoms and total coping. While, there was a highly statistically negative correlation between total coping of the studied parents and their total anxiety symptoms and total depressive symptoms.

\section{Recommendations}

(1) Psycho-educational program for all parents of deaf and mute child enrolled in school focused on reducing parent psychological distress.

(2) Assess the attitude and practice of dealing with the deaf and mute child for the whole family member and neighborhood through application of role modeling technique in the front of them to learn how to communicate.

(3) Counseling therapy for parent with deaf and mute child to lead their life in appositive way and improve psychological wellbeing necessity of training in effective coping strategies.

(4) Stress management program for parents about how to coping with stressors.

(5) Further studies for larger sample size should be done to generalize the results.

(6) Genetic counseling during premarital and antenatal should be encouraged for early detection of deaf and mute children.

(7) Screening test should be done for all infants for early diagnosis and management of deaf and mute child.

\section{References}

Alexander, T., \& Walendzik, G. (2016). Raising a child with Down syndrome: do preferred coping strategies explain differences in parental health? Psychology, (7), 28 - 39.

Alqahtani, A. (2015). The experiences of Saudi parents communicating with their children who are deaf at home. Unpublished manuscript. Greeley , CO: University of Northern Colorado.

Andrew, E. (2018). The psychological wellbeing of parents with deaf and mute child. Journal of the childhood. (2) 33-44.

Armstrong, E. (2020). The health-related quality of life in mothers of surviving deafblind adult children with congenital rubella syndrome.(3)44-55.

Asberg, K.K., Vogal, J.J \& Bowers, C. (2019). Exploring correlates predictors of stress in parents of children who are deaf: implications of perceived social support and mode of communication. Journal of child and family studies, 17, 486-499.

Barnard, M. (2018). The psychological stress of parents with deaf children. Journal of psychology.(6)455-555.

Bayat, M. (2019). Evidence of resilience in families of children with autism. Journal of Intellectual Disability Research, 51(9), 702714. Available at: https://doi.o rg/10.11 11/j.1365-2788.2007.00960.x. retrieved on 6/5/2020.

Beitmans, K. (2018). The psychological distress of parents with deaf and mute children. Mental and psychological health of deaf and mute children.(2)120-130.

Benjamin, O. (2019). The increased rate of deaf and mute children every year.(7)444555.

Butler, G. (2019). Definitions of stress. Occasional Paper (Royal College of General Practitioners), 61, 1-5. https:// www.ncbi.nl m.nih.gov/pubmed/ 8199583.

Carney, T (2020). Rights of intellectually disadvantaged people in $\mathrm{T}$ pagane \& Jwallace (Eds). Rights and freedoms in Australia, federation press (5) 54-62. Retrieved form: National Library of the Philippines, system. 
Carver, C.S., \& Scheier, M.F. (1989). Situational coping and coping dispositions in astressful transaction. Journal of personality and social psychology, 66 (1), 184-195.

Christiaan, K. (2019). the coping strategies of parents with deaf or mute children, Journal of psychology.(3)455-555.

Druss, B. (2019). The deaf children. Journal of child psychology. (1)33-44.

Dyson, L.L. (2020): Families of young children with handicaps: parental stress and family functioning. American Journal of mental Retardation, (95), 623-629. Retrieved form: National Library of the Philippines, system.

Folkman, S., \& Lazarus, R. S. (2019). If it changes it must be a process: Study of emotion and coping during three stages of a college examination. Journal of Personality and Social Psychology, 48(1), 150-170.

Forgays, D.K., Hasazi, J., E \& Wasserma, R.C. (2020). Recurrent otitis media and parenting stress in mothers of two year olds children. Journal of Developmental and Behavioral Pediatric. 13: 321-325. Retrieved form: National Library of the Philippines, system.

Humes, L. (2019). The World Health Organization's hearing-impairment grading system: an evaluation for unaided communication in age-related hearing loss. International journal of audiology, 58(1), 1220.

Katz, W. (2019). The psychological wellbeing of deaf children.Journal of child psychology. (2) 33-44

Lazarus, R. S. (2019). Coping theory and research: Past, present, and future. Psychom Medicine, (55), 234-247.

Lovibond, S.H., \& Lovibond, P.F. (1995). Manual for the depression anxiety \& stress scales $\left(2^{\text {nd }}\right.$ ed.): psychology foundation, (6)782-815.

Mahoney, M. (2020). The relationship between parenting stress and maternal responsiveness among mothers of children with developmental problems.(6) 344-444.

Martin, D. (2020). Sibling relationships of Deaf children. The impact of child and family characteristics. Rehabilitation Psychology. 47, 73-91.

McLaughline, K.A., Conron, K.J., Gilman, S.J., \& Koenen, K.C. (2012). Childhood adversity, adult stressful life events, and risk of past-year psychiatric disorder: a test of the stress sensitization hypothesis in a populationbased sample of adults. Comprehensive Psychiatry, 6(52), 111-135.

Montes, K. (2018). The Psychological functioning and coping among mothers of children with deaf and mute. (1) 233-333.

Nes, R.B., Roysamb, E., Hauge, L, J., Kornstadt, T., Landolt, M.A., Irgens, L.M., Eskedal, L., Kristenscen, P., \& Vollrath, M.E., (2014). Adaptation to the birth of a child with a congenital anomaly: A prospective longitudinal study of maternal well- being and psychological distress. Developmental Psychology, 50, 1827 - 1839.

Ostberg, M. (2019). Parenting stress and coping strategies. Journal of childhood. (2) 33-44.

Parish, S. L., \& Cloud, J. M. (2019). Financial well-being of young children with disabilities and their families. Social Work, 51(3), 223-232.available at: https://doi.o /10.1093/sw/51.3.223. Retrieved on 4/6/2020.

Price-Bonham, S. \& Addison, S. (2020). Families and mR children: An Emphasis on the father. Family Coordinator, 27 (3), 221229.

Quitter, A.L., Jackson, D.N. \& Gluekauf, R.L. (2019). Chronic parenting stress: moderating versus mediating effects of social support. Journal of personality and social psychology, (59), 1266-1278.

Sayed, S., Mounir, S., Mohamed, A., Nabil, A., \& Hassan, M. (2018). Assessment of psychological disorders in Egyptian children with hearing impairment. Sudanese Journal of 
Paediatrics, 18(2), 25.

Shilling, V., Morris, C., Thompson-Coon, J., Ukoumunne, O., Rogers, M., \& Logan, S. (2015). Peer support for parents of children with chronic disabling conditions: A systematic review of quantitative and qualitative studies. Developmental Medicine \& Child Neurology, 55(7), 602-609.

Shin, J. (2019). Structural modeling approach to the understanding of parenting stress. J Clin Child Psychol.; (29): 615-25.

Trute, B., Hiebert-Murphy, D., \& Levine, K. (2020). Parental appraisal of the family impact of childhood developmental disability: Times of sadness and times of joy. Journal of Intellectual \& Developmental Disability, 32(1), 1-9.

Weldon, S. (2018). "The Funniest tweets about people making noise during a quiet place." Cosmopolitan. April 9, 2018. (4) 4560.

Yamane, T. (1976). Statistics an introductory Analysis. $2^{\text {nd }}$ Edition, Harper and Row, New York. [Citation Time (s):2]. 


\section{الضغوط النفسية وإستراتيجيات التكيف لاي الأباء الذين لايهم أطفال صم وبكم رشا جلال عبد الرحمنـ معالي إبراهيم المالكي ـ مني ححم عبد العزيز بركات}

تعتبر حاسة السمع ضرورية لتعلم اللغة و الكلام وتنمية الإدر الك. ولذلك يعوق الصم و البكم النمو الطبيعي للطفل و القدرة الذهنية لكي يتعلم ويتو اصل مع الآخرين ،هذه الأطفال تتو اصل من خلال استخدام لغة الإشارة.

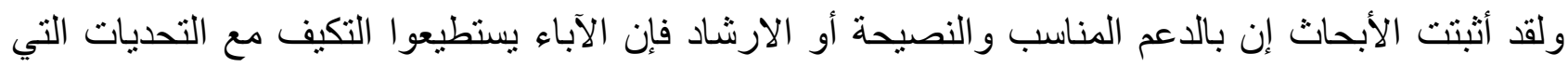

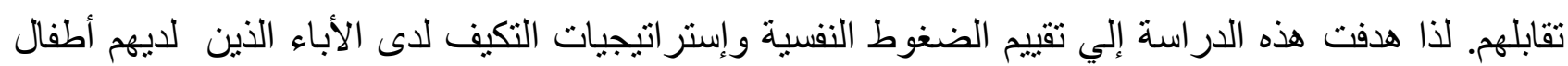

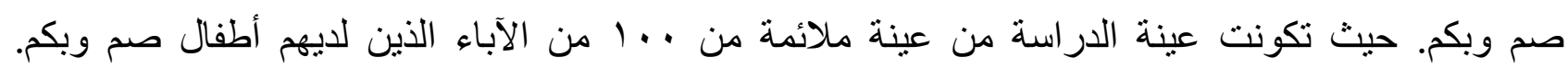

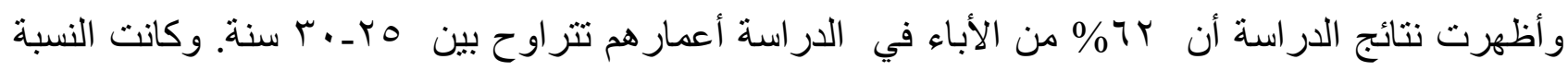

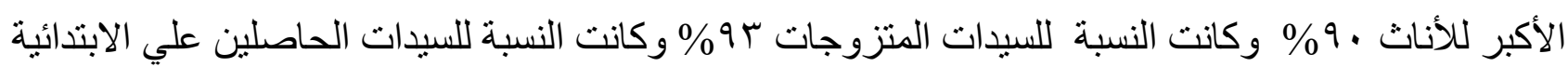
هي • †\% ـ في هذه الدراسة محاولة لتقييم الضغوط النفسية و إستر اتيجيات التكيف لدي الآباء الذين لديهم أطفال صم وبكم ، و أثبت الدراسة أن الآباء الذين لايهم أطفال صم وبكم يعانون من مستوي متوسط الإكتئاب و القلق

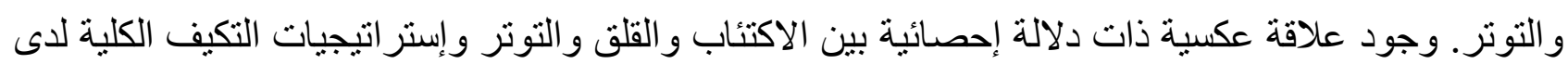

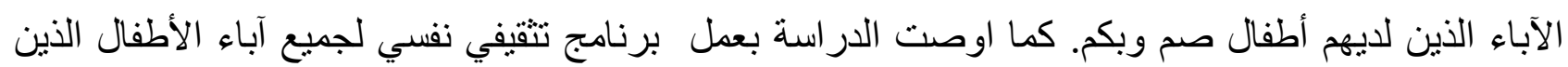

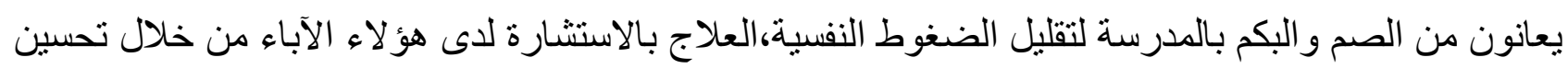

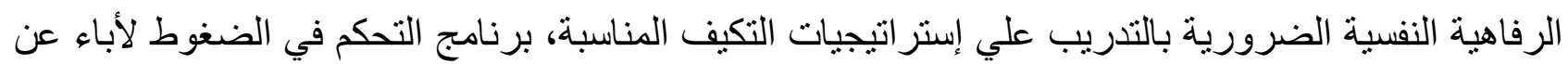
كيفية التكيف مع الضغوط. 